\title{
Letramentos e perspectiva discursiva dialógica: possibilidade de se observar a história de letramentos em textos escritos
}

\author{
Vanda Mari TROMBETTA (D) \\ Universidade Tecnológica Federal do Paraná (UTFPR)
}

\section{OPEN ACCESS}

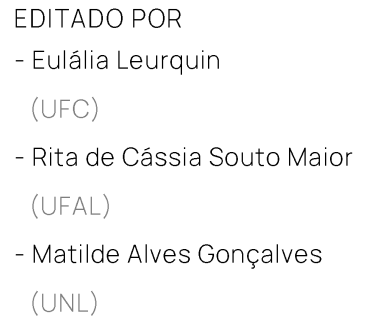

RESUMO

Ao realizar pesquisa na área de letramentos, uma das questões desafiadoras é: como observar os letramentos do escrevente na produção de texto? Em especial, para a Linguística Aplicada trata-se de uma questão instigante, pois embora haja vasto número de pesquisas na área, são poucas as pesquisas que não necessitem de entrevista, pois o cunho teórico e metodológico é o da pesquisa etnográfica. Com o propósito de refletir sobre outro modo de pesquisa, apresenta-se a perspectiva discursiva dialógica. Realiza-se, então, um cotejo entre as perspectivas destacando a princípio suas características e suas implicações. Prosseguese discorrendo sobre a investigação dos dados na perspectiva discursiva dialógica relacionada à história de letramentos. O corpus a ser analisado é composto de 2 redações do exame de vestibular da Fuvest de gênero dissertativo e o método delineado é o paradigma indiciário (GINZBURG, 1989) associado à Análise do discurso de Bakhtin e do Círculo e ao(s) Letramentos (KLEIMAN, 1995; 2007; SOARES 2005; STREET, 2003; 2012; 2014). Estabelece-se como objetivo deste estudo: buscar indícios da história de letramentos do escrevente na construção do objeto de discurso trabalho em redações de vestibular de cunho dissertativo. Os resultados apontam que a perspectiva discursiva dialógica relacionada à história de letramentos do escrevente baliza um encaminhamento para se observarem os letramentos nas produções escritas dissertativas. 


\section{REVISTA DA ABRALIN}

\section{ABSTRACT}

When conducting research in the area of literacies, one of the challenging issues is: how could the writer's literacies be perceived in the text production? Specially for the Applied Linguistics, that question is an intriguing one since, although there is plenty of research in the area, only a few projects do not require interviews, as the theoretical and methodological approach comes from the ethnographic research. The dialogic discursive perspective is presented in this study with the purpose to ponder about another research method. Thus, a comparison between those perspectives is made, highlighting initially their characteristics and implications. Subsequently, I expatiate on the investigation of the data from a dialogic discursive perspective related to the history of literacies. The corpus under analysis is formed of 2 essays written during a Fuvest university entrance examination and the chosen method is based on the indiciary paradigm (GINZBURG, 1989) associated with Bakhtin's and the Circle's Discourse Analysis and with Literacy - or the Literacies (KLEIMAN, 1995; 2007; SOARES 2005; STREET, 2003; 2012, 2014). The aim of this study is to search for signs of the history of the writer's literacies in the construction of "work" as the object of discourse in the Fuvestessays. The results indicate that the dialogic discursive perspective, related to the history of the writer's literacies, delineates a tendency for the analysis of literacies in essays.

\section{PALAVRAS-CHAVE}

Análise do Discurso. Objeto de discurso. Vozes sociais. Saberes formais e informais. Argumentos.

\section{KEYWORDS}

Discourse Analysis. Object of discourse. Social Voices. Formal and informal knowledge. Arguments.

\section{Introdução}

Ao realizar pesquisa na área de letramento, uma das questões desafiadoras é: como observar os letramentos do escrevente, na produção de texto, sem entrevistá-lo? Em especial para o ambiente educacional, trata-se de uma questão instigante, pois embora haja vastas pesquisas na área, a exemplo de Cerutti-Rizzatti (2012), Kleiman $(1995 ;$ 2007) e Soares (1998), são poucas as dedicadas à 


\section{REVISTA DA ABRALIN}

investigação de letramentos que não necessitem de entrevista (PASQUOTTE-VIEIRA, 2015; PRETTO; MOTTA-ROTH, 2018). Assim, pesquisar outros pontos de vistas teóricos e metodológicos para examinar os letramentos contribuiria em especial para a área da Linguística Aplicada e por conseguinte para o ensino.

Tendo em vista que o corpus, neste estudo, são redações de vestibular com o tema trabalho retoma-se a perguntadora norteadora: como buscar indícios de história de letramentos do escrevente na construção do objeto de discurso trabalho em redações de vestibular de cunho dissertativo? Parte-se do pressuposto de que o escrevente, com intuito de construir o objeto de discurso trabalho, traz diversas vozes sociais em forma de argumentos para dialogarem. De tal modo, podem-se observar as diferentes vozes sociais trazidas na história de letramentos por parte dos interlocutores e do próprio objeto de discurso, no que se refere ao tratamento do tema da redação trabalho.

Assume-se, com Faraco e Negri (1998, p. 165), que vozes sociais "são conjuntos difusos de visões de mundo (sistemas sociais de crenças) e elementos verbais." Desse modo, conceber um referente como "objeto de discurso" (MONDADA, 2001, p. 9) é vê-lo constituído a partir de diferentes vozes sociais identificáveis, visto trazerem posicionamentos marcados por diferentes grupos sociais. Parte-se do pressuposto de que um objeto de discurso é uma construção discursiva e não somente emanado de um espelhamento da língua em relação ao mundo (MONDADA; DUBOIS, 2003).

Em busca de resposta para a pergunta de início e no objetivo delineado para este estudo realizase um cotejo entre a perspectiva etnográfica e a perspectiva discursiva dialógica, apontando-se suas características e suas implicações. Na sequência, propondo um ponto de investigação para os dados coletados, apresenta-se a perspectiva discursiva dialógica relacionada à história de letramentos. Refere-se, em seguida, a metodologia para análise do corpus, 2 redações no total de 40, para, na extensão, estabelecer a discussão de resultados e as considerações finais do estudo.

\section{Perspectiva etnográfica interacional}

Os Novos Estudos do Letramento desenvolveram, conforme Street (2003; 2012; 2014), um trabalho que estabeleceu a etnografia como método de pesquisa. $\mathrm{O}$ autor admite que havia um ponto de ligação entre os pesquisadores, na análise de práticas de letramento, o foco na metodologia etnográfica (STREET, 2012). O método possibilita a análise de relatos do contexto social em que práticas letradas acontecem, pois permite "ver e ouvir" (STREET, 2014, p. 191) o que os participantes, de uma pesquisa, realizam. O pesquisador captaria imagens, modos de construção de práticas pela concretude da observação e confirmaria os dados pelas palavras, ao "falar com as pessoas" (STREET, 2003, p. 8). Tais motivos justificam a utilização de métodos e técnicas próximos com o trabalho de campo (STREET, 2012), pois é na inserção com o ambiente que o pesquisador terá contato com o dado e, por consequência, um entendimento das questões de pesquisa.

A pesquisa etnográfica, para Rocha e Eckert (2008, p. 2), impõe ao pesquisador o "deslocamento de sua cultura", para que possa compreender os modos de comportamento do ambiente investigado. 


\section{REVISTA DA ABRALIN}

Em outros termos, para os autores, o pesquisador a partir de tal deslocamento se vê imune de interferência tanto no modo de coleta (observação direta, conversas informais e formais, entrevistas) como na geração de dados. Em conformidade com tal pensamento, organizar-se-ia a coleta e a geração dos dados sem interferências, por exemplo, de uma perspectiva teórica adotada, de um lugar social e histórico de pesquisador, de interferência do pesquisador na organização das questões elaboradas, bem como de ser um estranho àquela cultura estudada.

Visto dessa maneira, ter contato como o sujeito e interagir no espaço situacional em que se encontra são significativas, já que a interlocução direta parece permitir ao pesquisador realizar uma leitura do fato isenta de intervenções, de juízos ou percepções de outrem; o fato falaria por si mesmo. Incidências como a presença do pesquisador no local do acontecimento e o contato com o sujeito empírico parecem, de acordo com os autores apontados, ser indispensáveis à pesquisa etnográfica.

\section{Perspectiva discursiva dialógica}

Com o intuito de discutir a pesquisa discursiva, parte-se da problematização construída por Corrêa (2011; 2013) sobre pesquisas etnográficas interativas. Refletindo quanto às fronteiras entre as perspectivas etnográfica e discursiva, o autor considera que assumir um tratamento discursivo dos dados implica destacar algumas questões teóricas. Guiada por essa posição, pontuam-se seis especificações basilares para uma pesquisa de cunho discursivo.

A princípio, assumir uma perspectiva discursiva passa pela redefinição do que é linguagem em uso, ou seja, é ir além da situação concreta de fala ou de escrita, é passar a considerá-la um "espaço em que as pessoas se fazem sujeitos no processo discursivo" (CORRÊA, 2011, p. 340). Esse espaço não está restrito ao encontro presencial, à interação face a face, tendo em vista que envolve espaço marcado "tanto pelo encontro presencial quanto pelos encontros em ausência" (CORRÊA, 2011, p. 340).

Estabelece-se, então, a segunda característica da perspectiva discursiva, as vicissitudes da perspectiva interacional presencial e da perspectiva dialógica. Enquanto a primeira aborda o encontro, do ponto de vista da presença, da necessidade de sujeitos empíricos dialogarem; a segunda trata do encontro do ponto de vista da presença e da não presença. Nesse sentido, os sujeitos participantes que falam/escrevem estão constituídos de outros encontros os quais os auxiliam a construir pontos de vista, representações do mundo, por exemplo.

Apresenta-se, à vista disso, a terceira característica destacada, a distinção teórica entre sujeito empírico e sujeito discursivo, o que, para Corrêa (2011, p. 341), estrutura-se na oposição "unicidade/não-unicidade". A unicidade do sujeito empírico é assimilada a uma identidade social e a um lugar ocupado por este na sociedade. Contrapondo-se a essa afirmação, Corrêa (2013) trata, não das características sociológicas, mas de como elas são representadas pelos sujeitos discursivos, problematizando-se, desse modo, a unicidade, visto que a constituição do sujeito da linguagem é redefinida pela "alteridade constitutiva de toda enunciação" (CORRÊA, 2013, p. 498). Ao assumir a noção de sujeito do 


\section{REVISTA DA ABRALIN}

discurso, tem-se a possibilidade de discutir as diversas posições enunciativas que o escrevente evoca, uma vez que é analisado como sujeito da enunciação, tendo sua existência no discurso.

Assume-se a noção de "posicionamento" de Charaudeau e Maingueneau (2004, p. 392), compreendida como uma "identidade enunciativa", no entanto, acrescenta-se que a identidade, segundo o princípio dialógico, só pode ser considerada na relação com o outro, posicionamento que cada escrevente assume de acordo com as relações de alteridade que mantém com seu interlocutor. Por conseguinte, o escrevente, ao instaurar uma identidade dialogicamente constituída a partir do interlocutor (não somente presencial), assume uma dentre várias posições enunciativas possíveis em um lugar de produção específico.

Nas redações de vestibular, por exemplo, o sujeito discursivo está envolto por diversos espaços sociais - vestibulando, aluno de ensino básico, filho, trabalhador, jovem - e, como tal, constrói um discurso assentado por esses lugares. O que é significativo para o estudo é que o escrevente vai revelando seu lugar social a partir da relação que emerge não somente com o interlocutor proposto, para o qual as redações são planejadas, mas com o outro que envolve distintos discursos historicamente construídos nos espaços sociais assumidos. Do mesmo modo, as identidades do escrevente se combinam em espaços e em tempos de interlocução diferentes, conforme os posicionamentos enunciativos.

Há de se reconhecer que o contexto de produção das redações de vestibular é avaliativo, de forma que os escreventes priorizam certas posições enunciativas as quais são signatárias de um discurso avalizado na universidade. A posição enunciativa do escrevente faz alusão ao contexto imediato, ao exame de vestibular, posteriormente outras posições enunciativas (aluno de ensino básico, filho, trabalhador, jovem) organizam outras alteridades no decorrer da escrita das redações. Tal questão faz reconhecer que o processo de enunciação, o exame de vestibular, mais do que organizar, impõe uma entoação para as vozes sociais que constroem os objetos de discurso. Nas palavras de Corrêa (2013, p. 498):

há um sujeito empírico ao qual não se pode negar uma realidade, por outro lado, seu aparecimento na linguagem nunca se dá de forma direta. O 'fato em si' da existência do sujeito empírico obedece à sempre problemática questão da referência. Mesmo numa perspectiva que só leve em conta a interação entre os sujeitos já não se pode conceber um sujeito plasmado na linguagem tal como em sua própria existência empírica. A referência (ao mundo, ao outro e a si mesmo) só acontece no processo de enunciação. Não se trata, pois, de uma relação linguagem/mundo (sem mediação), em que as coisas, as pessoas e o próprio sujeito apareceriam como tais na sua representação pela linguagem.

No excerto, o autor toca em duas questões importantes para a delimitação da noção de sujeito empírico e sujeito discursivo. Com relação à primeira, a existência da referência no processo de enunciação, conforme Benveniste (2005), apresenta marcas a dois ("eu" /"tu”) e a um espaço e tempo precisos; com Bakhtin (2010) a enunciação se revela uma relação envolvendo outros interlocutores além dos presenciais. A referência, desse modo, não trata de um nomear a realidade objetiva independente da enunciação; logo, o sujeito ao "historiciza[r] a ocupação do lugar" (2010, p. 341), que se refere à segunda questão, assume a posição enunciativa de sujeito discursivo elaborando significados, ocupando um lugar social, em um tempo e espaço singular na sociedade e na história, que se 


\section{REVISTA DA ABRALIN}

modifica de acordo com as diferentes relações de alteridade. Isso implica assumir que falar em referência é também abordar os diferentes posicionamentos do sujeito discursivo em cada enunciação.

A quarta ação é a especificação da noção de contexto extraverbal. Corrêa parte do ensaio Discurso na vida e discurso na arte: sobre a poética sociológica, de Voloshinov/Bakhtin (1926, s.d.), para tratar de outra fronteira entre a pesquisa etnográfica e discursiva - a noção de contexto extraverbal. Voloshinov/Bakhtin defendem que o discurso verbal não é autossuficiente, ou seja, é só ao lado da situação extraverbal que seu sentido se estabelece, é por esse viés que a exposição de Corrêa se desenvolve ao assumir que a relação de sentido está constituída pelo contexto extraverbal, e é sua compreensão que possibilita estabelecer o sentido de um enunciado.

Na quinta característica, Corrêa considera que os dados etnográficos integram as formulações específicas de um texto não são origem das formulações. A oposição do autor refere-se ao modo pelo qual a pesquisa etnográfica conduz a coletas de dados, denominada de uma pretensa "busca de origem", pois parte de "informantes tomados como ideais" e atribui às "incursões etnográficas o estatuto de investimento seguro no caráter supostamente unívoco dos dados" (CORRÊA, 2011, p. 334).

A ressalva do autor está na equivocada expectativa do pesquisador de pensar que estaria ele imune a diferentes interpretações por se encontrar afiançado pela metodologia da coleta dos dados, em contato com o ambiente do pesquisado ou mesmo pela sua observação dos dados. Se assim fosse, os dados retratariam a relação direta com o ambiente pesquisado e, desse modo, se chegaria ao par dado/realidade. Contudo, é necessário que seja considerada a intervenção do sujeito pesquisador no processo, de modo que os dados, mesmo com a pretensão de certa objetividade, própria do pesquisador, recebem, por exemplo, enfoque do quadro teórico no qual são analisados. Isso implica considerar que não há, então, relação direta com o dado; há, sim, observação com certa participação por parte do pesquisador.

Por essas razões, Corrêa (2011) propõe partir do texto escrito produzido, sexta ação para uma pesquisa discursiva. Assim, se é indispensável para a perspectiva etnográfica entrevistar o sujeito para gerar os dados, para a discursiva os dados etnográficos são considerados como "fatos de discurso simultâneos à formulação linguística" e não "refletiriam e comprovariam uma determinação (social e histórica) prévia ao contexto situacional" (CORRÊA, 2011, p. 335). Em outros termos, os dados não são somente resultado da situação imediata circunscrita nela mesma, visto se considerar que o enunciado não se configura como uma atividade de linguagem construída simultaneamente no momento da produção. Também como se notou, na terceira característica, o sujeito não é uno, o que significa dizer que o escrevente pode se apresentar a princípio por uma posição enunciativa que alude a elementos da situação pragmática enunciativa e, no decorrer das produções textuais, apresentar outras posições enunciativas que podem se referir a outras alteridades. As questões apontadas, na sexta ação, reiteram que se pode observar as posições enunciativas ao se partir do texto escrito produzido, sendo possível "dar um lugar para o sujeito que escreve" (CORRÊA, 2010, p. 14).

Contudo, para partir do texto escrito produzido, é preciso se sustentar sobre uma perspectiva teórica e metodológica definida e, neste estudo, assume-se a perspectiva discursiva. Adotar esta perspectiva para a construção deste estudo implica assumir noções compostas pela análise do 


\section{REVISTA DA ABRALIN}

discurso, na perspectiva de Bakhtin e o Círculo, visto seu arcabouço teórico considerar a dimensão sócio-histórica na produção do sentido e do sujeito do discurso.

Com base nas postulações expostas, assume-se que, para o estudo em letramentos na perspectiva discursiva, serão consideradas: a linguagem e as relações do escrevente com outros encontros - parte-se do encontro interacional, mas se atém à historicização do seu dizer, marcado pelas relações com outros encontros e representado por vozes sociais. Razão de se acrescer o termo dialógica à perspectiva discursiva, defendendo que o dizer não é construído somente pela interação imediata, mas pelo entrecruzamento de diferentes dizeres em temporalidades distintas. Logo, outras vozes sociais marcam a enunciação presencial; o escrevente que, ao enunciar, deixa-se representar por diferentes espaços sociais, desde assumir o espaço de vestibulando, de filho, de trabalhador, de jovem, a exemplo das redações em análise. Trata-se de um sujeito que enuncia a partir de diferentes espaços sociais. Ao ocupar um lugar representado por posições enunciativas na interação, na relação com o outro da interlocução, o escrevente torna histórico seu dizer. Então, não se fala mais apenas de um sujeito social, mas de diferentes posições enunciativas ocupadas pelo sujeito de linguagem.

\section{Perspectiva discursiva dialógica: história de letramentos}

Ao tornar histórico seu dizer, o escrevente apresenta traços da história de letramentos. Pensa-se ser possível ressaltar essa relação pela prerrogativa estabelecida na seção anterior, quando se mostra que "linguagem em uso" (CORRÊA, 2011, p. 334) é o espaço no qual o escrevente faz-se sujeito, tanto pelos atos de enunciação presencial como pelos não presenciais, marcados pelas réplicas ao já-enunciado, de maneira que, ao historicizar seu dizer, deixa indícios de um "conjunto de conhecimentos que o constituíram ao longo de sua formação" (CORRÊA, 2008). É por esses indícios que se concebe a história de letramentos do escrevente, para isso se valha de uma definição sobre arranjos temporais compondo esquemas textuais em Corrêa (2008b), que, embora distante de sua acepção no texto citado, parece fundamental para este estudo. Assume-se história de letramentos como "registros de temporalidades ligadas aos diferentes tipos de saber com os quais o sujeito teve contato", temporalidades que podem ter sido "vividas" em sentido pragmático, mas também podem ser "produto do narrado - imaginadas, por exemplo, com base no já ouvido/lido" (CORRÊA, 2008b, p. 76).

Ao registrar diferentes temporalidades na história de letramentos, o sujeito se põe diante de um registro de sua própria história que se manifesta em seus enunciados. A história de letramentos está submetida às particularidades temporais do acontecimento, em outros termos, a história de letramentos surge pela memória que "irrompe na atualidade do acontecimento" (COURTINE, 2014, p. 103). A partir do acontecimento, tem-se, então, a singularidade que vem à tona, não de um sujeito isolado do mundo, mas em função da alteridade estabelecida. 


\section{REVISTA DA ABRALIN}

Entre as possibilidades de se tratar a história de letramentos, é possível observá-la conjugada às diferentes dimensões sociais que o escrevente se deparou ao longo de sua formação. O reconhecimento de que os espaços sociais são muitos e diversificados possibilita abordá-los na perspectiva de duas grandes dimensões: a dimensão do saber formal e a dimensão do saber informal. Opta-se por essas dimensões por parecem ser espaços sociais com relação intrínseca com o corpus, composto de redações de vestibular, mas também com o percurso de um sujeito - a participação em uma instituição escolar e em outras instituições como a família, a igreja, o trabalho, grupos sociais entre outros. O intuito não é fazer um "inventário" (STREET, 2003, p. 9) da história de letramentos, mas pensar que por meio delas se pode mostrar indícios do modo como o escrevente, neste estudo, constrói o objeto de discurso trabalho.

As duas dimensões estão intrinsicamente ligadas aos termos "educação formal", "educação nãoformal" e "educação informal" (TRILLA, 2003, 2008). Antes de abordar os conceitos é importante destacar distinções entre os termos "educação" e "escola", pois pode auxiliar a entender as dimensões propostas. A educação é mais ampla e diversificada que a escola, por essa razão é um "fenômeno complexo, multiforme, disperso, heterogêneo, permanente e quase onipresente" (TRILLA, 2008, p. 29) e se apresenta em muitos espaços, como a família, a igreja, as associações, os centros comunitários, os meios de comunicação, entre outros, o que nos leva a considerar que a "educação não escolar sempre existiu" (TRILLA, 2008, p. 16).

A partir dos questionamentos entre os termos, principia-se o desenvolvimento de outros ambientes educacionais. A fim de esclarecimentos, com base nas pesquisas de Trilla $(2003,2008)$ e Touriñán (1996), conceitua-se: (i) a educação formal abrange o sistema educacional institucionalizado, cronologicamente graduado e hierarquicamente estruturado (da escola primária à universidade), como também abarca toda atividade sistemática, educativa, realizada fora do marco do sistema oficial; (ii) a educação informal é um processo em que as pessoas adquirem conhecimentos pelas experiências diárias e por sua relação com o meio em que vivem. Optou-se, por essa razão, tratar dos conhecimentos em duas dimensões: saberes da educação formal e saberes da educação informal. O vocábulo saberes é compreendido como produção de enunciado ligado a meios difusos de promoção de conhecimento.

Antes de prosseguir, é importante pontuar as especificidades e os limites difusos (TRILLA, 2003; 2008) dos saberes instaurados nas duas dimensões. Podem ser citados exemplos, a partir do autor, de atividades que apresentam limites difusos: no caso da leitura de pais para filhos, é tênue a linha da história como entretenimento e o momento da lição de ética, de moral, de orientação; o mesmo poderia se dizer da leitura de uma passagem bíblica. Ainda que a linha seja sutil e os limites difusos, não se altera a ordem das ações: há uma subordinação, os pais inicialmente leem as narrativas e somente na sequência partem para ensinamentos sobre determinados aspectos, como por exemplo nomes de animais. O mesmo processo ocorre no campo religioso, inicialmente a passagem bíblica é lida, e posteriormente constroem-se analogias aos fiéis. Em contraparte, na dimensão formal, os saberes, reforça o autor, apresentam-se de modo a se constituírem como não subordinados a outros, como no caso de um filme visto na instituição escolar cuja prerrogativa é o saber formal e posteriormente a arte, a 


\section{REVISTA DA ABRALIN}

diversão, o entretenimento. De modo semelhante, inicialmente não se concebe a leitura de um texto literário fruição, mas atrelada à sistematização e cronologia de uma escola literária.

Sintetizando, assume-se a dimensão formal como associada à instituição escolar, que no Brasil tem como uma das prerrogativas possibilitar ao educando o contato com práticas letradas acumuladas e legitimadas ao longo da história da humanidade. A instituição escolar é compreendida, na perspectiva de Bakhtin e o Círculo, como uma esfera da atividade humana em que circulam saberes específicos, pode-se citar como exemplo, saberes ligados às disciplinas que compõem o currículo escolar. Desse modo vozes sociais da História, da Sociologia, da Filosofia, da Matemática, entre outras, vão compondo a história de letramentos dos sujeitos. A outra dimensão, que constitui a experiência social, é a aprendizagem vivenciada pelo saber informal, que ocorre em diferentes espaços, cuja finalidade precípua não é a de herança de conhecimentos sistematizados. São aprendizagens vivenciadas ao longo da vida em espaços/instituições como família, igreja, trabalho, centros comunitários, mídia, legado cultural de antepassados, ditos populares, aprendizado obtido no dia a dia. Há reconhecimento de aprendizagens que compõem os saberes dos sujeitos passando pela redefinição do espaço e do tempo.

De acordo com essas prerrogativas, concebe-se que as dimensões do saber formal e do saber informal são indicativas das diferentes experiências sociais vivenciadas e estão coadunadas à história de letramentos do escrevente. Buscar indícios de letramentos oriundos dessas dimensões não significa estabelecer fronteiras rígidas entre elas; defende-se, sim, uma influência constante entre as duas. A fim de reforçar essa asserção, respalda-se nas considerações de Ginzburg (2006) a respeito de "circularidade cultural".

Com o intuito de refletir sobre a cultura popular e a cultura dominante, Ginzburg (2006) retoma pesquisas de Bakhtin. É a partir da análise, em especial, de Bakhtin (1996) na obra de François Rabelais que Ginzburg postula que, se, por um lado, tem-se "dicotomia cultural", uma vez que cada cultura tem suas especificidades; por outro, há "circularidade, influxo recíproco entre cultura" (GINZBURG, 2006, p. 15). É a hipótese de Bakhtin de uma influência recíproca entre as culturas que leva o historiador a propor e a ilustrar o conceito de "circularidade cultural" no livro O queijo e os vermes o qual destaca a figura de Domenico Scandella, conhecido por Menocchio.

Observa Ginzburg o fato de o discurso do protagonista apresentar um conjunto de ideias sobrepostas que iam do "radicalismo religioso ao naturalismo tendencialmente científico, às aspirações utópicas de renovação social" (2006, p. 19), de modo que o autor, a partir da leitura dos processos contra Menocchio, expõe diferentes passagens no decorrer do livro mostrando um processo de leitura resultado da circularidade entre as culturas. Em uma das passagens o historiador especifica o que lhe parece ser significativo para entender essa circularidade no modo de leitura do moleiro: um "filtro" que de "maneira inconsciente interpunha entre ele e a página impressa" fazendo-o: i) enfatizar certas passagens enquanto ocultava outras; ii) exagerar o significado de uma palavra, isolando-a do contexto (GINZBURG, 2006, p. 89). Esse filtro "agia sobre a memória de Menocchio deformando sua leitura", e é ele que faz o moleiro "remete[r] continuamente a uma cultura diversa da registrada na página impressa: uma cultura oral" (GINZBURG, 2006, p.89). O encontro entre posições de um 


\section{REVISTA DA ABRALIN}

moleiro - com acesso restrito a materiais escritos e discussões sobre as temáticas abordadas em seus depoimentos - e de grupos intelectuais - com acesso a múltiplas leituras e discussões -, reforça a tese, para o autor, a respeito da circularidade da cultura.

Considera-se, à vista disso e com as reservas feitas anteriormente, a circularidade entre as dimensões do saber formal e informal como uma categoria analítica aplicável às experiências sociais do escrevente. Como categoria, auxilia a conjugar dados para o estudo, criando a aproximação entre a construção do objeto de discurso e a história de letramentos. Não se intenciona nomear ou classificar com precisão as vozes sociais que compõem as dimensões, mas vislumbrar certa especificidade que indica sua procedência. A especificidade de sua procedência é vista associada à esfera, ao gênero, à posição enunciativa dos interlocutores e à história de letramentos dos escreventes que circulam entre vozes sociais do saber formal e do saber informal.

\section{Metodologia e análise}

Para propor uma metodologia de análise, integram-se conceitos dos campos da Análise do Discurso (Bakhtin e o Círculo), o dos Letramentos ao campo do paradigma indiciário (GINZBURG, 1989), procurando, nas análises, buscar indícios de letramentos do escrevente na construção do objeto de discurso trabalho.

O historiador Carlo Ginzburg é reconhecido no campo das Ciências Humanas por trabalhar e propor um modelo epistemológico, que coaduna pesquisas qualitativas à observação de detalhes, denominado de paradigma indiciário (GINZBURG, 1989). Com base no paradigma indiciário e associado à perspectiva dialógica de Bakhtin e o Círculo, este estudo busca indícios deixados nas redações de vestibular que permitam caracterizar a atividade do escrevente no seu trabalho com a linguagem, marcado, sempre, por pistas dialógicas.

Nem sempre os indícios se mostram facilmente ao pesquisador, visto a necessidade de uma interpretação de uma realidade. Dessa maneira, é preciso localizar "zonas privilegiadas" (GINZBURG, 1989, p. 177) para observação de um texto. Adotando uma perspectiva dialógica, Corrêa (1998a, p. 170) defende que o estabelecimento dessas zonas privilegiadas depende da "reconstrução da dialogia, em que tanto os ecos longínquos como as interlocuções diretas têm seu papel reconhecido". A dialogia referida por Corrêa envolve tanto o diálogo imediato que o escrevente estabelece com seu destinatário quanto o mais longínquo, com o já-dito. Assertiva que faz vislumbrar indícios de história de letramentos advinda de diferentes temporalidades, expondo a circularidade entre os diferentes saberes.

Ao adotar o paradigma indiciário e o quadro teórico da análise do discurso, é possível recuperar fenômenos que influenciam a construção dos indícios materializados, concomitantemente no que há de específico da situação enunciativa e no que há de elementos estabilizados nas interações ao longo da história. O indício revela o sócio-histórico que surge na significação.

Para operacionalizar a análise, primeiramente se observam os argumentos, organizados a partir das vozes sociais em duas perspectivas: 1) vozes do saber formal: emergência de saberes 


\section{REVISTA DA ABRALIN}

estritamente escolarizados provenientes das diferentes disciplinas (História, Filosofia, Sociologia, Literatura, Arte); 2) vozes do saber informal: emergência de saberes não estritamente escolarizados (da cultura de massa, do dito popular, da religião, da família). Com o intuito de evidenciar as análises para as questões postas, apresentam-se duas redações do conjunto de 40 redações de vestibulandos da Fuvest. As duas redações foram selecionadas devido ao fato de serem mais representativas de acordo com o objetivo da pesquisa. Da prova de redação, fazia parte uma coletânea e uma instrução (prova disponível em https://acervo.fuvest.br/fuvest/2006/fuv2006_2fase_por.pdf). Da instrução, constavam três orientações: (1) ler três textos da coletânea que apresentam diferentes visões de trabalho; (2) relacionar esses três textos e com base nas ideias neles contidas, além de outras que julgar relevantes; (3) redigir uma dissertação em prosa. Apresentam-se dois fragmentos de redações representativas do corpus para posterior discussão dos dados.

\section{Fragmento 1}

As diversas faces do trabalho

$1 \S[\ldots]$ o trabalho foi utilizado como meio de sobrevivência [...] desde que surgiu e até hoje pode-se dizer que a base da sociedade e da sobrevivência dos homens está no trabalho.

$2 \S$ Muitas espécies de animais [...] utilizam-se deste como meio de sobrevivência [...]

$3 \S[\ldots]$ Pássaros constroem seus ninhos, castores fazem barragens [...].

$4 \S[\ldots]$ acreditava-se que na medida em que o desenvolvimento tecnológico e a capacidade de produção aumentassem o trabalho diminuiria. Com o advento do sistema capitalista, o trabalho só fez aumentar. [...]

$5 \S$ O trabalho também é o sentido da vida de alguns. [...] Muitos vêem em seus trabalhos a razão de sua existência [...] uma forma de ocupar seu tempo em vida. Isso é mais válido ainda no que tange ao trabalho artístico. Talvez este seja o que mais consome espiritualmente os homens. Um artista costuma dedicar sua vida à sua obra.

$6 \S$ Diz-se, popularmente, que o ócio é o ofício do diabo. Sendo assim, é provável que o trabalho seja intrínseco ao homem e que jamais desapareça.

O fragmento explicita a construção de um ethos (cf. MAINGUENEAU, 2008) relacionado a "trabalho", ou seja, a elaboração da imagem que o escrevente cria para o próprio objeto de discurso. Logo, pensar sobre o modo como o escrevente cria um ethos para "trabalho" é pensar em sujeito e, portanto, em voz social. O título, As diversas faces do trabalho, antecipa o objeto de discurso a ser desenvolvido, as características multifacetadas que o trabalho tem, os diversos rostos. O escrevente constrói essas diversas faces ao trazer argumentos formado por vozes sociais que abordam o objeto de discurso.

O título deste texto personifica o objeto de discurso "trabalho". De outro modo, indiretamente constrói um corpo para esse objeto de discurso e também para o próprio texto, o qual é organizado de acordo com uma enumeração de argumentos. Considera-se, neste texto, que as "faces" abordadas no texto do vestibulando são as vozes sociais falando sobre ele. Nesse recurso de organização do 


\section{REVISTA DA ABRALIN}

texto por enumeração, isto é, na própria construção composicional, pode-se observar o diálogo que o escrevente faz com as diferentes vozes sociais e o desenvolvimento do texto vai mostrar aquela para a qual ele dá preferência. Esse diálogo com diferentes vozes impõe certas escolhas que constituem um estilo específico, embora não individual do escrevente em torno de certa dialogicidade com vozes do saber formal.

A primeira "face" apresentada retoma vozes do saber ligado às disciplinas curriculares das ciências humanas - História e/ou Sociologia: meio de sobrevivência de pequenos agrupamentos de humanos; base da sociedade e da sobrevivência dos homens. A segunda "face", disparada pelo segundo texto da coletânea, retoma da voz social da tecnologia a crítica de que o desenvolvimento tecnológico só fez o trabalho aumentar. A terceira "face" cita a voz do saber religioso: trabalho é o sentido da vida de alguns; razão de existência. A quarta "face", sustentada pela voz de valorização do trabalho de arte, é disparada pelo terceiro texto da coletânea: forma de ocupar tempo em vida (...) mais válido ainda no que tange ao trabalho artístico; este (trabalho artístico) consome espiritualmente os homens.

O escrevente encerra o texto com uma expressão que tem a forma de um dito popular, o ócio é o ofício do diabo, o qual, ao retomar um saber religioso, liga-se a uma valoração religiosa, concluindo com a possibilidade de ser o trabalho um meio para se manter distante do diabo, argumento que sustentaria a tese de que o trabalho não desaparecerá jamais.

A imagem criada pelo escrevente para o objeto de discurso "trabalho" é como uma "voz' indissociável de um corpo enunciante historicamente especificado" (MAINGUENEAU, 2008, p. 17), ou seja, a(as) voz(vozes) expõe(m) manifestações do já-dito tornando visíveis pontos de vista fomentados ao longo da história. No exemplo da redação em análise, as manifestações do já-dito estão dialogando com pontos de vistas de uma circularidade pelo saber formal. Ainda no texto analisado, pode-se conceber a elaboração de um corpo para o objeto de discurso também como uma tentativa de o escrevente dialogar com a banca e construir um ethos para si, mostrando competência interpretativa ao trazer diferentes vozes a respeito do tema "trabalho" ao longo da história.

O diálogo estabelecido no texto com as diferentes vozes sociais está conjugado a uma história de letramentos que aponta para o saber formal e para um diálogo com a universidade e, mais particularmente, a banca de correção), avalizado por uma ideia de que o trabalho, sendo fundamental na sociedade, é um componente da sociedade.

\section{Fragmento 2}

Em resposta ao transitório (o trabalho é resposta a ameaça da morte)

$1 \S$ Trabalhar é deixar um legado. Levada a considerar a hipótese de serem vencidas as barreiras da mortalidade, a revista Superinteressante previu que, não houvesse a ameaça constante da morte, o ser humano diminuiria sem ritmo de produção expressivamente, afinal a perspectiva do fim é o combustível do homem. [...]

$2 \S$ Trabalho [...] escravo, assalariado, informal, compulsório - existe desde que a história virou ciência. [...] um dos fundamentos do contemporâneo, está para a idade atual assim 


\section{REVISTA DA ABRALIN}

como a religião está para a Idade Média; estão intrinsecamente relacionados, não há vida sem feitos.

$3 \S[\ldots]$ faça-se lembrar as reformas luterana e calvinista e a importância irrefutável que tiveram na disseminação do protagonista desta dissertação. Foi naquela conjuntura que se passou a entrar no céu pelas realizações em vida, e não pelas possibilidades aquisitivas de cada um.

$4 \S[\ldots]$ que Simões e Marques permitam a discrepância: a pior coisa que poderia acontecer ao mundo é a banalização dele em prol de ainda mais hedonismo. [...]

$5 \S$ Torcer por um universo em que seja possível viver em sesta é regressista e até utópico demais - é a Utopia de Thomas More, a Sociedade Alternativa de Raul Seixas e Paulo Coelho. [...] o elo entre a vida e o tema central, a ânsia por produzir deve-se ao caráter efêmero das pessoas [...]. A obra de um homem só existe para que, através dela, ele alcance a eternidade.

No fragmento 2, há três conjuntos de vozes sociais. O primeiro enfatiza trabalho como produto (feitos, realizações, obra); o segundo, como processo (trabalhar, produção, trabalho, produzir); e o terceiro demonstra a situação específica das vozes sociais para referir-se ao objeto de discurso "trabalho" na situação de enunciação (protagonista desta dissertação, tema central).

O primeiro conjunto, trabalho como produto, remete a argumentos permeados por vozes sociais do saber religioso: não há vida sem feitos. Se passou a entrar no céu pelas realizações em vida. A obra de um homem só existe para que, através dela, ele alcance a eternidade.

O segundo conjunto mostra o trabalho como processo, faz referência a argumentos que trazem a voz social do capitalismo: Trabalhar é deixar um legado; se não houvesse a ameaça constante da morte, o ser humano diminuiria seu ritmo de produção expressivamente, afinal a perspectiva do fim é o combustivel do homem; Trabalho - seja ele escravo, assalariado, informal, compulsório - existe desde que a história virou ciência. A ânsia por produzir deve-se ao caráter efêmero das pessoas. Pode-se observar uma circularidade nesse conjunto entre os saberes formais e informais pelo emprego de referências como a revista Superinteressante, a canção Sociedade alternativa e obras consideradas clássicas do conhecimento formal, como Utopia.

O terceiro conjunto remete a argumento que constituídos de vozes sociais da disciplina curricular de História e vozes sociais das aulas de produção de texto: faça-se lembrar as reformas luterana e calvinista e a importância irrefutável que tiveram na disseminação do protagonista desta dissertação; que se retome o elo entre a vida e o tema central. Ao recuperar saberes das aulas de História, o escrevente expõe saberes considerados importantes nas circunstâncias em que o texto está sendo escrito. Ao expor reminiscências dos vocábulos aprendidos nas aulas de produção textual, o escrevente expõe também um "ethos [que] implica uma maneira de se mover no espaço social" (MAINGUENEAU, 2008 , p. 18) em que o texto está sendo escrito - o exame de vestibular. Ao concluir o texto, o escrevente propõe que A obra de um homem só existe para que, através dela, ele alcance a eternidade remetendo à voz social do saber religioso. 


\section{REVISTA DA ABRALIN}

A circularidade com que se move o escrevente entre os saberes correspondentes às diversas vozes sociais expõe sua história de letramentos. A intenção da circularidade é o de legitimar seu discurso suscitando adesão à universidade - pelo discurso avalizado por argumentos permeados da voz do discurso religioso. Nesse exemplo, o escrevente dialoga, amparado pela força de persuasão que situa o trabalho na perspectiva de ser um elo entre vida e eternidade.

\section{Resultado e discussões}

Nos dois exemplos, os escreventes trazem para seus textos vozes sociais de diferentes espaços sociais. Trata-se de vozes sociais que participam do diálogo com diferentes temporalidades, seja da coletânea fornecida na prova de redação, seja da circularidade entre os saberes formais e informais. Como se observou, as vozes sociais inscritas nem sempre se marcam por meio da utilização das aspas ou verbos discendi, mas de certo modo são reconhecíveis, visto que, segundo Bakhtin, "a palavra não esquece jamais seu trajeto" (BAKHTIN, 1982, p. 263, apud AMORIM, 2009, p. 13). É por deixar indícios desse trajeto que há a possibilidade de reconhecer na história de letramentos os saberes formais e informais.

Saberes marcados por uma junção de vozes sociais, das quais participam as diversas experiências sociais com as quais o escrevente foi se apropriando ao longo de sua existência sócio-histórica. Contudo, as escolhas do escrevente não são neutras porque, ao se constituir pelo outro no discurso, está circunstanciado pelas imposições do processo de enunciação (o gênero, a banca de correção, o exame de vestibular, expectativas pessoais, familiares, escolares, da universidade), concebido, nesta pesquisa, não apenas como a situação imediata de enunciação, mas por outras enunciações, relacionadas ao contexto sócio-histórico em que vive/viveu.

\section{Considerações finais}

Propôs-se, neste estudo, a buscar indícios da história de letramentos do escrevente na construção do objeto de discurso trabalho em redações de vestibular de cunho dissertativo. Para tal investigação, optou-se por analisar a história de letramentos pela perspectiva discursiva dialógica.

Assume-se, então, para a pesquisa discursiva dialógica que sejam consideradas: as relações do escrevente com outros encontros - parte-se do encontro interacional, mas atem-se à historicização do seu dizer, marcado pelas relações com outros encontros e representado por vozes sociais. Concebe-se, também, que o escrevente, ao enunciar, deixa-se representar por diferentes espaços sociais, é um sujeito que enuncia a partir desses diferentes espaços. Ao ocupar um lugar representado por posições enunciativas, na relação com o outro da interlocução, que o escrevente delineia sua história de letramentos. Portanto, não se fala mais de sujeito empírico, mas de um sujeito discursivo, que vai se construindo ao longo das produções. 


\section{REVISTA DA ABRALIN}

Pode-se dizer que a história de letramentos mostra o processo dialógico do escrevente, de certo contato com as vozes sociais do saber formal e informal, como também, assinalaria não somente os anos de escolaridade, mas igualmente a influência de outros espaços sociais.

Entender o papel da escola no debate sobre letramentos significa perceber que o escrevente circula entre os saberes e o resultado desse diálogo poderia, a exemplo do foco deste estudo, indicar as vozes sociais trazidas para construir o objeto de discurso. O entendimento das características de uma pesquisa discursiva dialógica e a circularidade entre os saberes são razões que sugerem ser possível observar indícios da história de letramentos nas produções escritas de gênero dissertativo sem entrevistar o produtor do texto.

Este estudo procurou observar indícios da história de letramentos do escrevente letramentos na construção do objeto de discurso trabalho em redações de vestibular de cunho dissertativo, pesquisas futuras podem ampliar resultados analisando mesmos ou diferentes objetos de discursos em outros gêneros discursivos.

\section{REFERÊNCIAS}

BAKHTIN, M. M. Estética da criação verbal. 4. ed. São Paulo: Martins Fontes, 2010.

BENVENISTE, E. Problemas de linguística I. Campinas: Pontes, 2005.

CERUTTI-RIZZATTI, M. E. Letramento: uma discussão sobre implicações de fronteiras conceituais. Educação e sociedade. V. 33, n. 118, p. 291-305, jan./mar. 2012.

CORREAA, M. L. G. Letramento e heterogeneidade da escrita no ensino de português. In: SIGNORINI, I. Investigando a relação oral/escrito. Campinas: Mercado das Letras, 2008a.p. 135-166.

CORRÊA, M. L. G. Arranjos referenciais de tempo em textos de pré-universitários: letramento e oralidade. Gragoatá, n. 25, p. 75-93, 2. sem. 2008b.

CORRÊA, M. L. G. As perspectivas etnográfica e discursiva no ensino da escrita: o exemplo de textos de préuniversitários. Revista da Abralin, p. 333-356, 2011.

CHARAUdeaU, P.; MAINGUENEAU, D. Dicionário de análise do discurso. São Paulo: Contexto, 2004.

COURTINE, J. J. Análise do discurso político: o discurso comunista endereçado aos cristãos. São Carlos: Edufscar, 2014 .

KLEIMAN, A. B. Modelos de letramento e as práticas de alfabetização na escola. In: KLEIMAN, A. B. (Org.). Os significados do letramento: uma nova perspectiva sobre a prática social da escrita. Campinas: Mercado de Letras, 1995. p. 15-61.

KLEIMAN, A. B. Letramento e suas implicações para o ensino de língua materna. Revista Signo, Santa Cruz do Sul, v. 32 n 53, p. 1-25, dez, 2007. Disponível em:

<http://online.unisc.br/seer/index.php/signo/article/viewFile/242/196>. Acesso em: 20 jan. 2021. 


\section{REVISTA DA ABRALIN}

GINZBURG, C. Sinais: raízes de um paradigma indiciário. In: GINZBURG, C. Mitos, emblemas, sinais. São Paulo: Cia. das Letras, 1989. p. 143-180.

GINZBURG, C. O queijo e os vermes: o cotidiano e as ideias de um moleiro perseguido pela Inquisição. São Paulo: Cia. das Letras, 2006.

MAINGUENEAU, D. A propósito do ethos. In. MOTA, A. R.; SALGADO, L. (Orgs.). Ethos discursivo. São Paulo: Contexto, 2008, p. 11-32.

MONDADA, L. Gestion du topic et organisation de la conversation. Caderno de Estudos Linguísticos, n. 41, p. 7-35, jul./dez.2001.

MONDADA, L.; DUBOIS, D. Construção dos objetos de discurso e categorização: uma abordagem dos processos de referenciação. In: CAVALCANTE, M. M.; RODRIGUES, B. B.; CIULLA, A. C. (Orgs.) Referenciação. São Paulo: Contexto, 2003, p. 17-52.

PASQUOTTE-VIEIRA, E. A. Letramentos Acadêmicos: a aliança entre linguística e etnografia. Estudos linguísticos, 44 (2): p. 695-710, maio-ago. 2015. Disponível em file:///C:/Users/asuspc/Downloads/1005-2850-1-SM.pdf. Acesso em: jun. de 2021.

PÊCHEUX, M. A análise automática do discurso. In: GADET, F.; HAK, T. (Orgs.). Por uma análise automática do discurso: uma introdução à obra de Michel Pêcheux. Campinas: Ed. da Unicamp, 1997. p.61-161.

PRETTO, A.; MOTTA-ROTH, D. Investigando etnografia em pesquisas sobre letramentos acadêmicos. Disciplinarum Scientia. Série: Ciências Humanas, v. 19, n. 2, p. 303-316, 2018. ISSN 2179-6890 https://doi.org/10.37780/ch.v19i2.2927

ROCHA, A. L. C.; ECKERT, C. Etnografia saberes e práticas. Iluminuras, v. 9, n. 21, 2008. Disponível em: <http://seer.ufrgs.br/index.php/iluminuras/article/view/9301/5371>. Acesso em 07 junho de 2021.

SOARES, M. B. Alfabetização e letramento. São Paulo: Contexto, 2005.

STREET, B. Abordagens alternativas ao letramento e desenvolvimento. In: TELECONFERÊNCIA UNESCO BRASIL. Letramento e diversidade, outubro de 2003.

STREET, B. Perspectivas interculturais sobre o letramento. Filologia: linguística portuguesa, n. 8, p. 465-488, 2007.

STREET, B. Literacy and multimodality. STIS Lecture: Inter-Disciplinary Seminars. Faculdade de Letras, Laboratório SEMIOTEC - FALE/UFMG, v. 9, p. 1-25, 2012a. Disponível em: $<$ http://arquivos.lingtec.org/stis/STIS-LectureLitandMMMarch2012.pdf>. Acesso em: jun. de 2021.

STREET, B. Eventos de letramento e práticas de letramento: teoria e prática nos novos estudos do letramento. In. MAGALHÃES, I. (Org.). Discursos e práticas de letramento: pesquisa etnográfica e formação de professor. Campinas: Mercado das Letras, 2012b. p.69-92.

STREET, B. Letramentos sociais: abordagens críticas do letramento no desenvolvimento, na etnografia e na educação. São Paulo: Parábola, 2014.

TOURIÑÁN, J. M.L. Análisis conceptual de los processos educativos. Teor. Educ., Ediciones Universidad de Salamanca, n. 8, p. 55-79, 1996.

TRILLA, J. B. La educación fuera de la escuela: ámbitos no formales. Barcelona: Ariel, 2003. 


\section{REVISTA DA ABRALIN}

TRILLA, J. B. A educação não formal. In: ARANTES, V. M. (Org.). Educação formal e não-formal. São Paulo: Summus, 2008. p.15-55.

VOLOSHINOV, V.; BAKHTIN, M. M. [1926]. O discurso na vida e o discurso na arte: sobre poética sociológica. Tradução Carlos Alberto Faraco, Cristovão Tezza, (s.d.). Tradução para fins didáticos. 